\title{
Community Notification of Maternal, Neonatal Deaths and Still Births in Maternal and Neonatal Death Review (MNDR) System: Experiences in Bangladesh
}

\author{
Animesh Biswas',2*, Fazlur Rahman², Charli Eriksson', Koustuv Dalal1 \\ ${ }^{1}$ Department of Public Health Science, School of Health and Medical Sciences, Örebro University, Örebro, \\ Sweden \\ ${ }^{2}$ Centre for Injury Prevention and Research, Bangladesh (CIPRB), Dhaka, Bangladesh \\ Email: animesh.biswas@oru.se, animesh@ciprb.org
}

Received 10 July 2014; revised 28 August 2014; accepted 10 September 2014

Copyright $@ 2014$ by authors and Scientific Research Publishing Inc.

This work is licensed under the Creative Commons Attribution International License (CC BY). http://creativecommons.org/licenses/by/4.0/

(c) (i) Open Access

\section{Abstract}

Objectives: The aim of the study was to examine the process of community maternal, neonatal deaths and still births notification within the Bangladesh government health structure using the Maternal and Neonatal Death Review (MNDR) system. The study also explored the feasibility and acceptance of community death notification in the MNDR system. Methods: The study was undertaken in the Thakurgaon district of Bangladesh during 2010. During the study a mix of both qualitative and quantitative information was collected. A review of the documentation process of community death notification was undertaken and focus group discussions (FGDs) with community members, health care providers and managers in a sub-district were conducted, with in-depth interviews (IDIs) with district heath and family planning managers. Quantitative data were collected from community death notifications in the district during January to December 2010. Results: The death notification process was implemented by the government health care system within the Thakurgaon district. Field level health and family planning staff collected maternal and neonatal death information, recorded the death on the notification form and reported back to the Upazila (sub-district of the district) focal point at the Upazila health complex (primary health care centre). Community people were encouraged to share their death information to field level health staff. The health and family planning managers in the district periodically discussed the maternal and neonatal deaths and prepared remedial action plans in high death notified areas. In 2010, 59 maternal deaths, 739 neonatal deaths and 633 still births were reported in Thakurgaon district. District health and family planning departments performed community death notification as part of their routine daily work and integrated these procedures with other field level activities. Con-

\footnotetext{
Corresponding author.
}

How to cite this paper: Biswas, A., Rahman, F., Eriksson, C. and Dalal, K. (2014) Community Notification of Maternal, Neonatal Deaths and Still Births in Maternal and Neonatal Death Review (MNDR) System: Experiences in Bangladesh. Health, 6, 2218-2226. http://dx.doi.org/10.4236/health.2014.616257 
clusion: Community death notification under the MNDR system was found to be achievable and acceptable at the district level using the existing government health system. The simple death notification process used to capture community level maternal, neonatal deaths and still births provides a guide for planning corrective actions for better health outcomes for the community.

\section{Keywords}

\section{Community Death Notification, Maternal and Neonatal Death, Bangladesh}

\section{Introduction}

Every year, it is estimated that worldwide there are 500,000 maternal and 4 million newborn deaths, it is also estimated that another 3 million babies are stillborn around the world. Most maternal and infant deaths occur in low and middle income countries, and many are preventable [1]. It is acknowledged that Bangladesh is progressing well towards achieving the Millennium Development Goal (MDG) 5 of reducing the maternal mortality by three-quarters between 1990 and 2015 [2]. In 2010, the United Nations (UN) recognized Bangladesh for its exemplary progress towards MDG 4 in child mortality and for being on-track to achieve the maternal mortality reduction [3]-[6]. During the past four decades, the country has experienced a substantial reduction in maternal and neonatal mortality. Maternal mortality has been reduced from 574 deaths per 100,000 live births in 1991, to 194 deaths per 100,000 live births in 2011. Similarly, neonatal mortality has also been reduced to 32 per 1000 live births [7]. However, maternal and neonatal mortality in Bangladesh is currently still too elevated for the country to achieve MDGs [8].

The country finds it challenging to report each maternal, neonatal death and still birth in the community. There is difficulty in getting information on deaths including death review at the district level for Bangladesh at present does not have any routine inbuilt system for identifying deaths or their cause. Different death review systems are practiced in many countries around the world to address maternal and neonatal death [9]-[14] Therefore, Bangladesh has started to develop and implement a maternal and neonatal death review (MNDR) system. This system has been adopted from a World Health Organization [WHO] model "Beyond the Number" in a district during 2010 under the joint GoB-UN Maternal and Neonatal Health Initiatives (MNHI) [15]. Community death notification is one of the major components of the MNDR system which allows death notification reporting within the community by the government health and family planning staff. The death notification information is useful to prepare local action plans, addressing death dense areas and also in indentifying underlying causes of death. The current study aims to examine the process of community death notification through the existing government health system using the MNDR system and also to explore its feasibility and acceptance to strengthen the existing system.

\section{Methods}

The study was piloted though the existing government health system in Thakurgaon district in 2010. The District, with a population of $1,450,000$, is situated in the northern part of Bangladesh approximately 450 kilometers from the capital Dhaka. Qualitative and quantitative information regarding community death notification and its feasibility and acceptance was collected in the study. Qualitative information was collected through FGDs and IDIs and quantitative data collected from the number of maternal, neonatal deaths and still births reported in the district from January to December 2010.

MNDR is an evidence based intervention that notifies all maternal, neonatal deaths and still births and cross examines the causal factors of deaths either medical or social though verbal and social autopsy. The system also follows with appropriate actions to reduce maternal and neonatal deaths. The approaches are beyond just counting deaths but are to develop an understanding of why the deaths happen and how they can be prevented [16].

Documents outlining the process of the development of death notification in MNDR system have been reviewed and these include; death notification tools, guidelines, log frame, a list of MNDR committees and their term of references and minutes of meetings. The MNDR system has also been officially endorsed through a letter from the Directorate General of Health Services (DGHS) and Directorate General of Family Planning (DGFP) 
under the Ministry of Health and Family Welfare (MOHFW) of the Government of the People's Republic of Bangladesh.

A qualitative method was used to examine the feasibility of community death notification in MNDR in Pirganj Upazila of Thakurgaon before commencement of the research in the $1^{\text {st }}$ week of January 2010. Two focus group discussions were undertaken with grass root level health and family planning staff and their managers. These included an Upazila Health \& Family Planning Officer (UHFPO) and Upazila Family Planning Officer (UFPO) and community representatives. Another two in-depth interviews were also conducted with the district Health Manager, Civil Surgeon (CS) and family planning manager and the Deputy Director of Family Planning (DDFP) (Table 1).

After one year (January to December 2010) of conducting community death notifications in MNDR system, $2^{\text {nd }}$ time qualitative data was collected with the similar group by conducting two FGDs and two IDIs to explore acceptability and effect of the community death notification. This was carried out in the $2^{\text {nd }}$ week of January 2011.

A group of skilled researchers including data collectors and anthropologists were engaged in qualitative data collection. All FDGs were performed in the local language (Bengali), and from collected audio-recordings and hand notes, transcripts were prepared and translated in English and were analyzed thematically. Two public health researchers reviewed the MNDR documents and evaluated the findings.

Quantitative data was obtained from notified maternal, neonatal deaths and still births in the district during January to December 2010. All data was entered into statistical software, SPSS 11.5 for Windows and a descriptive analysis was performed.

The following operation definitions were used to report deaths from the community.

Maternal death: The death of a woman while pregnant or within 42 days of the end of the pregnancy, irrespective of the duration and the site of the pregnancy, from any cause related to or aggravated by the pregnancy or its management, but not from accidental or incidental causes.

Neonatal death: The death of live-born infants on, or before 28 days postpartum.

Still birth: Any fetus born without a heartbeat, respiratory effort or movement, or any other sign of life at or after 28 weeks' gestation.

\section{Results}

\subsection{Process for Community Death Notification in MNDR System (Review Documents)}

Community death notification in the MNDR system was built on a coordinated and supportive policy environment at the national level by the DGHS in collaboration with the DGFP, Ministry of Health and Family Welfare of Government of the People's Republic of Bangladesh under a Joint GoB-UN Maternal Neonatal Health Initiative. The MNDR is an evidence based maternal and neonatal health intervention that determines the total number of maternal and neonatal deaths and identifies the medical and social causes behind the deaths. It provides reliable information for appropriate actions to improve the quality of $\mathrm{MNH}$ services in order to reduce further maternal and neonatal mortality and morbidity.

It was agreed to introduce MNDR within the existing health care system using available government resources at the district level. The system provides confidentiality, anonymity and non blaming participation for community members throughout the entire process. A national level technical team from the DGHS and DGFP was responsible for developing tools, guidelines and the implementation framework. Community death notification in MNDR was adopted from the "Beyond the Number"-death surveillance cycle, implemented by the World Health Organization. A community death notification form was developed and endorsed by the technical group, thereby allowing for the collection of death information from the community (Figure 1). A supervisory and monitoring mechanism was established in participation with national level health and family planning managers, professional experts and different stakeholders under the auspice of the National MNDR committee. Official Government official letters from both health and family planning directories were issued for the district, supporting the piloting of the system.

Grass root level health and family planning staff, included a health assistant (HA) and family planning assistant (FWA), were assigned to notify any maternal, neonatal deaths and still births from the community within three to seven days and report to the primary health care centre within the Upazila health complex. An Upazila level MNDR committee for each of the Upazila of the district and another district committee was developed to supervise and monitor the progress. Field staff reported community death notification information to an assigned 
Table 1. Participants in the qualitative study.

\begin{tabular}{crr}
\hline Qualitative instruments & Age range & Participants \\
FGD (2) & $35-55$ yrs & $\begin{array}{r}\text { Health Assistant (1), Family Planning Assistant (1), Health Inspector (1), Family Planning Inspector } \\
\text { (1), EPI Technician (1), Sanitary Inspector(1), Upazila Health and Family Planning Officer(1), } \\
\text { Upazila Family Planning Officer (1) and Statistician (1). }\end{array}$ \\
FGD (2) & $20-62$ yrs & $\begin{array}{r}\text { Community volunteers (2), Community clinic management committee member (2), local elite (1), } \\
\text { school teacher(1), Imam (1), Political leader (1), Elected member from local government (1) } \\
\text { IDI (4) }\end{array}$ \\
$50-56$ yrs & Civil Surgeon, Deputy Director Family Planning \\
\hline
\end{tabular}

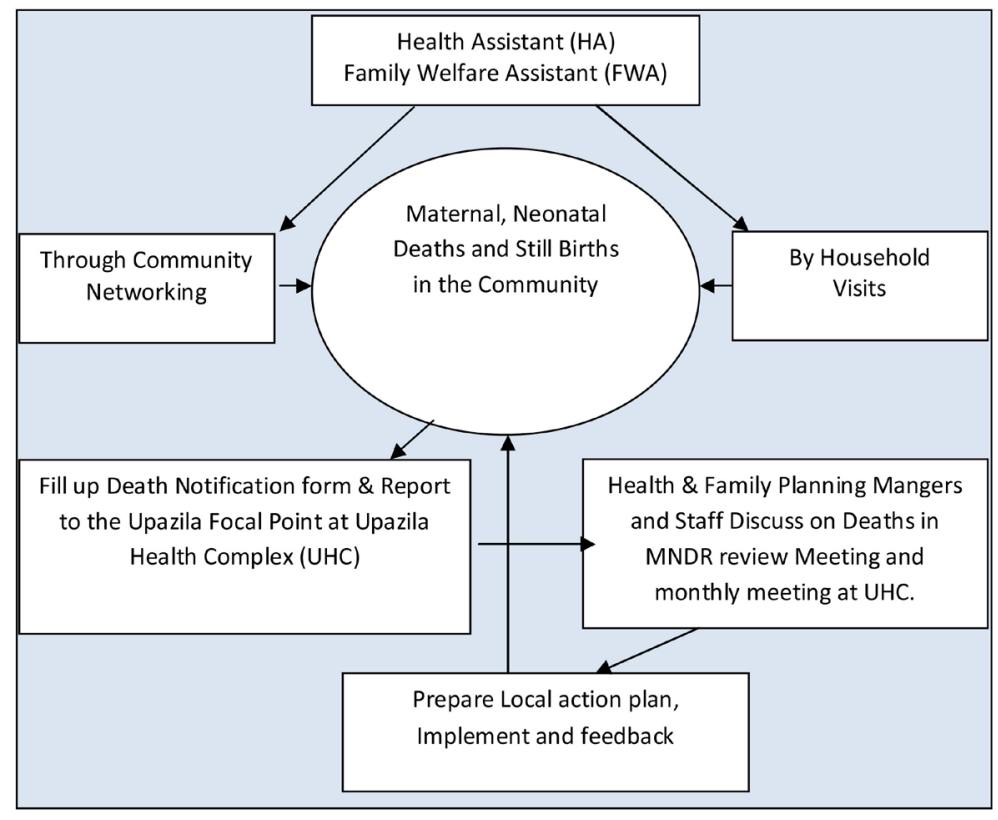

Figure 1. Community death notification system.

focal point in the Upazila. The review committee at each Upazila was also responsible for discussing death numbers and preparing a local level action plan.

A total of 872 government field staffs, volunteers and NGOs workers were trained to oversee death notifications during the implementation of the system. An area distribution per health worker was agreed upon for identification and notification of deaths; this eased the task to cover a community population of about 6000 persons per health worker. There was no overlapping in distribution area among health staff and family planning staff. In addition each field level worker facilitated networking among community clinic members, volunteers, teachers, social workers and NGO workers of the locality for early identification of any relevant death event. Every death was confirmed by the assigned health staff during home visitation before filling a notification form.

\subsection{Examine Feasibility of Community Death Notification in MNDR}

Before the initiation of death notifications within the MNDR system, two FGDs and two in-depth interviews were conducted to examine the feasibility of the system at a sub-district level using developed tools, guidelines and processes. During the FGD with grass roots level health and family planning staff, it was mentioned that death notification was possible and could be implemented within their routine activities. It was accepted that death information could be retrieved if both the health and family planning departments worked together under comprehensive joint micro planning. Furthermore, they also mentioned that using community death notification, a yearly picture of maternal and neonatal health status of the district could be identified, and based on deaths report different preventive action plans could be taken for the improvement of maternal and newborn health services.

One HA said "We have a scope to visit at household level and as we run a satellite clinic in the villages for immunization of children under the age of five, it is also possible to collect death information." 
Another HA mentioned, "We are responsible for covering the entire community, so we follow a monthly work plan. Death notification could be our special focus and it could reflect in our monthly work plan.”

FWA described that some of the places where there were overlaps between health staff and family planning staff at the grassroots level, "We might require separate micro plan for the areas where health and family planning workers have overlapping areas."

Another FWA reported, "Death notification might take a month or more than that. We are doing household visit, two months a cycle, so if a death occurs after the regular visit, it will take next cycle to report it."

The Upazila health \& family planning officer (UHFPO) who is manager of health complex in Pirganj Upazila stated, "Death notification can be possible using a community network, death information can be collected from different group include non-government organization (NGO) volunteers, community group in the community clinic or someone in the village could inform about a maternal, neonatal death to the health and family planning field staff."

The Upazila family planning office (UFPO) who is the head of family planning department in the Pirganj Upazila demonstrated his commitment, "Although we have a number of challenges in the field including different tasks, family planning staff will be happy to report deaths. Initially it may take some time to orient with the new activity, it will be better with progression of time".

The UFPO also expressed the view that, "Sometimes it might be difficult to get death information in early neonate case or still birth by definition. It's also important to perform capacity building for field level staff on death notification and orientation on using the death notification form."

Another FGD with community members was undertaken to understand how the community responds to a death notification. The community members stated that they did not have any obligation to provide information on maternal and neonatal deaths, however, the deceased family would usually be happy to provide information if the government field level worker clearly mentioned the reasons for collecting data from the household. The community people also expressed that health and family planning field level staff are very well know in the community, due to the fact that they have been working for many years, so they have a good acceptance at the household to collect any health information.

One of the participant mentioned, "If any death occurs in the village, the community people inform the field level health staff."

Another participant stated, "We have still a number of social barriers. If any still birth occurs in the community, we often didn't report this to field level health staff; rather we use to hide the sad issue because society will look on us differently."

One of the villagers said, "It is important to share the reason for collecting information from the village and how the data will be used. For it will make the village people to speak up. We have shyness in talking about death issues because the community people think there might chance of using the information to convict someone in a police case."

During in-depth interviews, the district head authority from health department, the Civil Surgeon and the Deputy Director of Family Planning all indicated that they were satisfied that through the planned MNDR system that all deaths would be notified in an integrated manner. Managers also strongly believed that the initiative would work and be accepted by the community.

The Civil Surgeons stated; "The health department was always committed to capture maternal and newborn deaths, however in many cases; there are number of challenges in the field to achieve this including, geographical distribution, human resources distribution etc. If the health and family department work together then it is quite possible to capture the record of deaths from the community."

The Deputy Director of Family Planning observed that, "At the field level, family planning staff visits each household every two months, so there is always the possibility to under report. Now MNDR has an enormous scope to practice a joint micro plan to work together with the health department to report each death.”

\subsection{Acceptance of Community Death Notification in MNDR}

The target groups were revisited a year after the operation of the death notification system in MNDR to explore its acceptance. During the FGD with the health providers it was found community death notification in MNDR is an achievable component within the health system. Though this process, all maternal and neonatal deaths were recorded and a number of areas reporting high deaths and low deaths were identified. The discussion also 
indentified that the work was achievable within the exiting heath system by both directorates. The data generated in 2010 is very useful and can focus the health progress and priorities in each district.

During FGD, one health field staff HA mentioned, "This is a special initiative. At the beginning we were not really aware but later we are able to work jointly with family planning staff to report deaths to the Upazila health complex."

One of the FWA reported that, "Now it has come to our knowledge that there are a number of deaths, including neonatal death and still birth, of which we were unaware of before MNDR. I have a community network that report deaths to me and the villagers have my cell phone number to communicate."

Upazila health mangers and family planning mangers illustrated that they are getting a greater number of deaths than in 2009 which was obviously reflected an under reporting during that year. UFPO mentioned in FGD, “We didn't capture all deaths before 2010. We reported to higher authorities that our Upazila doesn’t have any maternal or newborn deaths but now the truth becomes clear. Many deaths were under reported but now our field level staff are committed to report those under reported deaths."

UFPO described, "We have started to utilize the data in periodic review meeting to discuss and analyze a number of areas identified with high deaths, including maternal deaths, though the Upazila meeting, a number of local action plans were prepared and implemented in the district to hopefully reduce such a burden in future years."

Community people during the FGD stated that now the community is ready to report deaths to the health and family planning worker. Staff are now searching at the community level and indentifying death cases. One of the members said, "The villagers overcome hesitations, now they know that utilization of the information is only for the betterment of health status of the community, they feel proud to contribute.”

The district mangers from health and family planning department were highly satisfied with reported community deaths and are now committed to continue MNDR throughout the year. The Civil surgeon in particular said, "We don't need to guess what our death numbers will say. We are fortunate for even we found a huge number of deaths in the community we can calculate and compare to the national maternal mortality ratio and neonatal mortality rate."

During IDI, the DDFP of the district illustrated that monthly reported deaths were discussed in district monthly coordination meeting and in the review meeting. The data used for mapping of deaths on the map with red dots for maternal death, yellow dots for neonatal death and blue dots for still birth. The dotted map of the district was useful for visualization and for health and family planning managers to see the progress and undertake preventative initiatives in the areas where deaths are clustered and occurring.

\subsection{Community Maternal, Neonatal Deaths and Still Births in 2010}

Field level government staff from health department and family planning department notified 59 maternal deaths, 739 neonatal deaths and 633 still births in Thakurgaon from January to December 2010 (Table 2). Some of the Upazilas had high maternal deaths and within certain Upazilas death dense areas were identified, necessitating immediate steps for improvement (Figure 2).

\section{Discussion}

Bangladesh has successfully developed and introduced a community based death notification process within its health system. It captures all maternal, neonatal deaths and stillbirths in one of the representative district of Bangladesh. Death notification has been undertaken by the government field staff of both health and family

Table 2. Community death notification in Thakurgaon, 2010.

\begin{tabular}{cccc}
\hline Sub district & Maternal death & Neonatal death & Still birth \\
\hline Sadar & 23 & 207 & 162 \\
Baliadangi & 7 & 131 & 107 \\
Pirgonj & 6 & 132 & 120 \\
Ranishonkoil & 13 & 172 & 122 \\
Haripur & 10 & 97 & 122 \\
Total & 59 & 739 & 633 \\
\hline
\end{tabular}




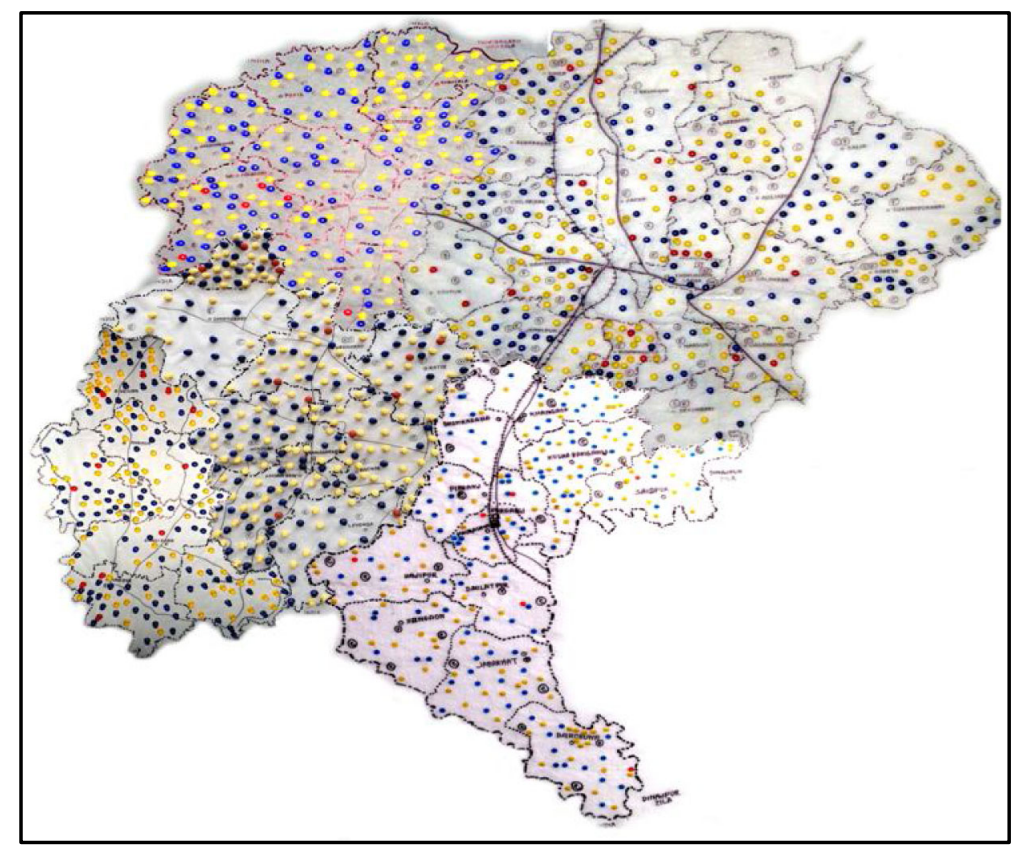

Figure 2. Death mapping of Thakurgaon District 2010.

planning departments under joint collaboration. The implementation of death notification provides a good example of collaboration between health and family planning departments and Non Government Organization (NGO) sectors utilizing networks of volunteers from within the community. Integration of the new activity in the existing health system was easily accomplished with highest coverage for death notification.

Death Enquiry is fundamentally health service-based, and data is collected largely through review of records and notification forms submitted from the health facility where the deaths usually occurred [17]. Notification of a large numbers of deaths using already existing structures was further eased by applying area distribution, a well practiced process for other primary health programs [18] in Bangladesh. In South Africa in particular, a mandatory notification of maternal deaths, with rigorous investigation through the National Committee on Confidential Enquiries into Maternal Deaths, has been an important national intervention to quantify the problem and monitor trends [19] [20]. Participation of households, relatives and community people in reporting death notification reflected a high acceptance of the system in the community. The wider coverage and its integration into regular routine works without being perceived as a burden to field staff indicates the feasibility and acceptability of the process within the health system.

The death notification in turn led to exploration of medical and social causes, a difficult process especially for developing countries [19] [21]. The numbers from death notification were simply used in Death Mapping and estimates of mortality rates were calculated by categories. This attracted attention of the managers and providers in initiating interactive discussion to identify needs-based remedial actions. Thus, the death notification under MNDR intervention provides a useful ongoing Information System on maternal and neonatal mortality in low resource countries like Bangladesh where surveillance or extensive health system data is difficult to determine.

High-quality data on maternal and neonatal deaths, particularly from rural areas, is especially important given that these areas have the highest burden of mortality and the least reliable data [22]. International consensus holds that maternal deaths are usually under-registered with great variability across geographic areas [23] [24].

A number of remedial actions were implemented by utilizing the data from death notifications during the period. The outcome remained visible and well appreciated at the local and national level as an encouragement for health system responses. Community participation in the process and the development and implementation of the remedial action plan has resulted in a positive response to death notification.

\section{Conclusion}

Low income countries like Bangladesh still have challenges in data availability on maternal, neonatal death and 
still birth. A health led "death notification system” might be used for monitoring progress or planning in the area. Experiences in the Thakurgaon district will form a basis to scale up to a national level and can be utilized in other countries with similar settings.

\section{Acknowledgements}

The research has been implemented by the Directorate General of Health Services (DGHS) in collaboration with Directorate General of Family Planning (DGFP), Ministry of Health and Family Welfare (MOHFW) of Government of the People's Republic of Bangladesh under a Joint GoB-UN Maternal Neonatal Health Initiatives. We are thankful to DGHS and DGFP. We are also grateful to the UNICEF, Bangladesh for providing technical and financial support through UKaid, European Union and Canadian CIDA.

\section{Conflict of Interest}

We have no competing interests to declare

\section{References}

[1] Silal, S.P., Penn-Kekana, L., Harris, B., Birch, S. and McIntyre, D. (2012) Exploring Inequalities in Access to and Use of Maternal Health Services in South Africa. BMC Health Services Research, 12, 120. http://dx.doi.org/10.1186/1472-6963-12-120

[2] Koblinsky, M., Anwar, I., Mridha, M.K., Chowdhury, M.E. and Botlero, R. ( 2008) Reducing Maternal Mortality and Improving Maternal Health: Bangladesh and MDG 5. Journal of Health, Population and Nutrition, 26, $280-294$.

[3] Chowdhury, A.M., Bhuiya, A., Chowdhury, M.E., Rasheed, S., Hussain, Z. and Chen, L.C. (2013) The Bangladesh Paradox: Exceptional Health Achievement Despite Economic Poverty. The Lancet, 382, 1734-1745. http://dx.doi.org/10.1016/S0140-6736(13)62148-0

[4] El Arifeen, S., Christou, A., Reichenbach, L., Osman, F.A., Azad, K., Islam, K.S., Ahmed, F., Perry, H.B. and Peters, D.H. (2013) Community-Based Approaches and Partnerships: Innovations in Health-Service Delivery in Bangladesh. The Lancet, 382, 2012-2026. http://dx.doi.org/10.1016/S0140-6736(13)62148-0

[5] Adam, A.M., Ahmed, T., El Arifeen, S., Evans, T.G., Huda, T. and Reichenbach, L. for Lancet Bangladesh Team (2013) Innovation for Universal Health Coverage in Bangladesh: A Call to Action. The Lancet, 382, 2104-2111. http://dx.doi.org/10.1016/S0140-6736(13)62150-9

[6] Das, P. and Horton, R. (2013) Bangladesh: Innovating for Health. The Lancet, 382, 1681-1682. http://dx.doi.org/10.1016/S0140-6736(13)62294-1

[7] NIPORT, MEASURE Evaluation, icddr,b. (2012) Bangladesh Maternal, Mortality and Health Care Survey 2010. National Institute of Population Research and Training, MEASURE Evaluation, and International Centre for Diarrheal Disease Research, Bangladesh, Dhaka.

[8] Sharma, G. (2012) Maternal, Perinatal and Neonatal Mortality in South-East Asia Region. Asian Journal of Epidemiology, 5, 1-14.

[9] Ronsmans, C. and Graham, W.J. (2006) Lancet Maternal Survival Series Steering Group. Maternal Mortality: Who, When, Where, and Why. The Lancet, 368, 1189-1200. http://dx.doi.org/10.1016/S0140-6736(06)69380-X

[10] UNICEF, India (2008) Maternal and Perinatal Death Inquiry and Response MAPDIR.

[11] South Asian Institute for Policy Analysis and Leadership (SAIPAL) (2010) Report on Maternal and Perinatal Death Review (MPDR).

[12] Puri, M., Malia, K., Aryal, D.R., Shrestha, M., Hulton, L. and Pradhan, A.S. (2008) Maternal and Perinatal Death Review in Nepal. Access on 12 July 2014.

[13] Waiswa, P., Kallander, K., Peterson, S., Tomson, G. and Pariyo, G.W. (2010) Using the Three Delays Model to Understand Why Newborn Babies Die in Eastern Uganda. Tropical Medicine \& International Health, 15, 964-972.

[14] Kongnyuy, E.J. and van den Broek, N. (2008) The Difficulties of Conducting Maternal Death Reviews in Malawi. BMC Pregnancy Childbirth, 8, 42.

[15] World Health Organization (2004) Reviewing Maternal Deaths and Complications to Make Pregnancy Safer, Beyond the Numbers.

[16] Biswas, A., Rahman, F., Halim, A., Eriksson, C. and Dalal, K. (2014) Maternal and Neonatal Death Review (MNDR): A Useful Approach to Identifying Appropriate and Effective Maternal and Neonatal Health Initiatives in Bangladesh. Health, 6, 1669-1679. http://dx.doi.org/10.4236/health.2014.614198 
[17] Tollman, R.W.S., Kahn, K. and Penn-Kekana, L. (2007) Health and Demographic Surveillance Sites Contribute Population-Based Data on Maternal Deaths in Rural Areas. South African Medical Journal, 97, 944-945.

[18] Mayer Hashi Project/Engender Health Report (2010) Community-Based Distribution of Misoprostol for the Prevention of Postpartum Hemorrhage: Evaluation of a Pilot Intervention in Tangail District, Bangladesh. Access on 20 July 2014.

[19] Kalter, H.D., Mohan, P., Mishra, A., Gaonkar, N., Biswas, A.B., Balakrishnan, S., Arya, G. and Babille, M. (2011) Maternal Death Inquiry and Response in India the Impact of Contextual Factors on Defining an Optimal Model to Help Meet Critical Maternal Health Policy Objectives. Health Research Policy and Systems, 9, 41. http://dx.doi.org/10.1186/1478-4505-9-41

[20] Pattinson, B. (1998) Saving Mothers: Report on the Confidential Enquiry into Maternal Deaths in South Africa. Department of Health, Pretoria.

[21] Supratikto, G., Wirth, M.E., Achadi, E., Cohen, S. and Ronsmans, C. (2002) A District-Based Audit into the Causes and Circumstances of Maternal Death in South Kalimantan, Indonesia. Bulletin of the World Health Organization, 80, 228-234.

[22] Weiner, R., Tollman, S., Kahn, K. and Penn-Kekana, L. (2007) Health and Demographic Surveillance Sites Contribute Population-Based Data on Maternal Deaths in Rural Areas. South African Medical Journal, 97, 944-945.

[23] Ronsmans, C. and Graham, W.J. on behalf of Lancet Maternal Survival Series Steering Group (2006) Maternal Mortality: Who, When, Where and Why. The Lancet, 368, 1189-1200. http://dx.doi.org/10.1016/S0140-6736(06)69380-X

[24] AbouZahr, C. and Wardlaw, T. (2003) Maternal Mortality at the End of a Decade: Signs of Progress? Bulletin of the World Health Organization, 79, 561-568. 
Scientific Research Publishing (SCIRP) is one of the largest Open Access journal publishers. It is currently publishing more than 200 open access, online, peer-reviewed journals covering a wide range of academic disciplines. SCIRP serves the worldwide academic communities and contributes to the progress and application of science with its publication.

Other selected journals from SCIRP are listed as below. Submit your manuscript to us via either submit@scirp.org or Online Submission Portal.
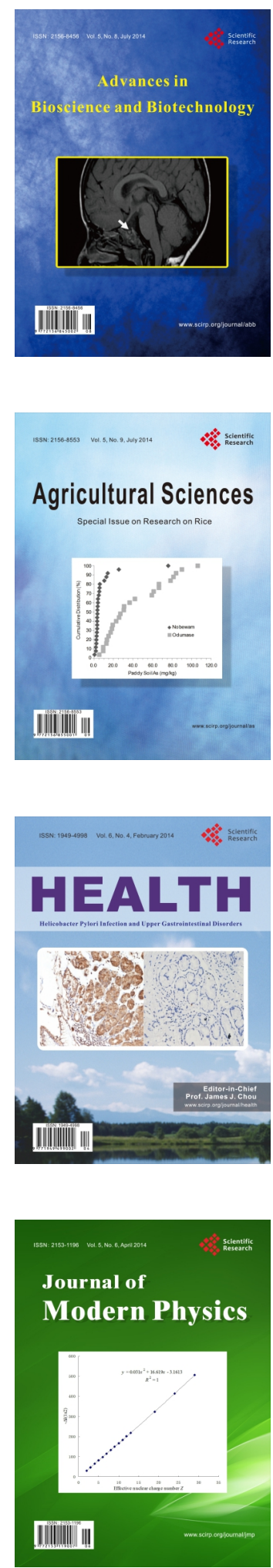
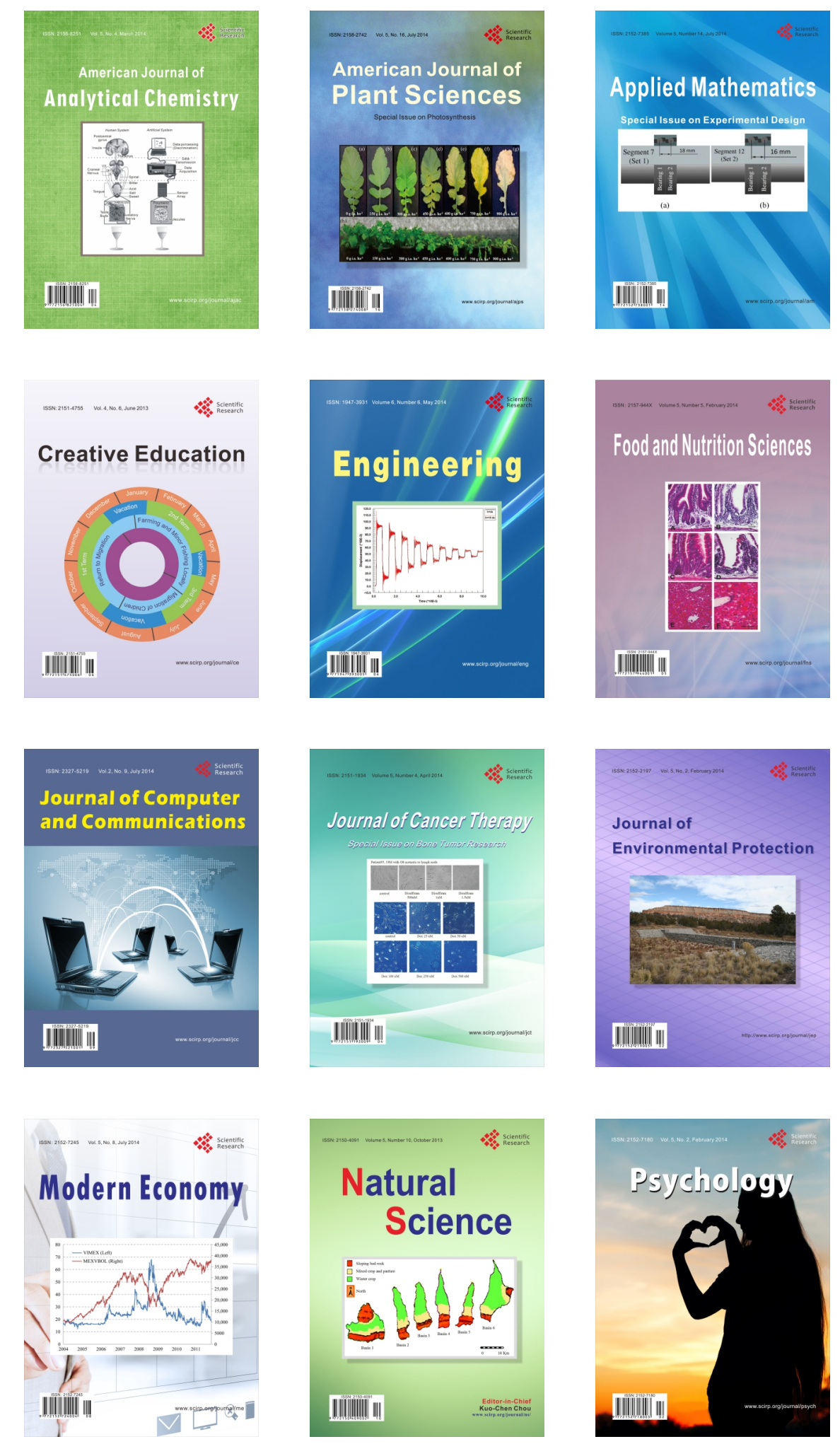